\title{
Ein Apparat zur schnellen Reinigung beliebig großer Mengen von Sand und Kies.
}

\author{
Von Dr. Wilhelm Lorch. \\ Mit 2 Figuren.
}

Bei einer großen Anzahl pflanzenphysiologischer Experimente, bei Keimungsversuchen, bei der Instandsetzung von Aquarien bedarf man gut gereinigten Sandes oder Kieses, und zwar oft in bedeutender Menge. Soviel mir bekannt, nahm man die Reinigung des Sandes bisher in der Weise vor, daß man ihn in einem zum Teil mit Wasser gefüllten und verschließbaren Glaszylinder so lange hin und her schleuderte, bis das Wasser über dem ruhenden Sande vollständige Klarheit zeigte. Diese Methode, Sand $\mathrm{zu}$ reinigen, ist aber so unsauber, zeitraubend und anstrengend, daß es sich wohl lohnte, die Konstruktion eines Apparates ins Auge zu fassen, der alle diese Übelstände ausschließt und es gestattet, in kürzester Zeit große Mengen Kies und Sand vorzüglich $\mathrm{zu}$ reinigen.

Der Apparat besteht im wesentlichen aus einem kräftigen Zinkzylinder (Fig. $1 a$ ), an dessen oberen Rand ein Trichter (Fig. 1 und $2 c$ ) angelötet ist; an den unteren Rand setzt sich gleichfalls ein Trichter (Fig. 1b) an, der einen weit gebohrten

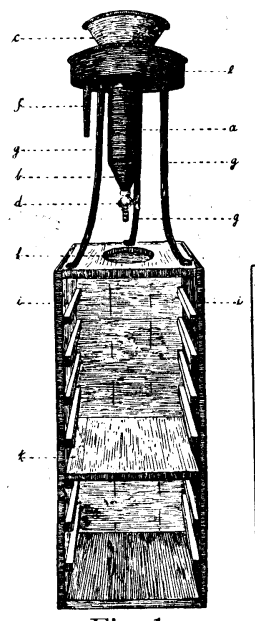

Fig. 1.

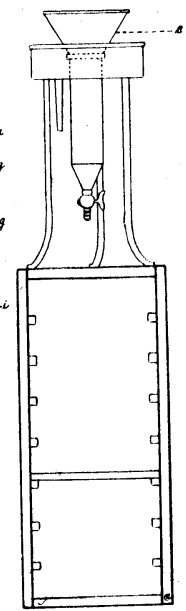

Fig. 2. Gashahn (Fig. 1d) trägt. Mit dem oberen Teil des Zylinders ist ein ringförmiges Gefäß (Fig. 1c) durch Lötung fest verbunden, in dem sich das über den Rand des oberen Trichters überfließende Wasser ansammelt und durch eine am Boden angebrachte weite Röhre (Fig. $1 f$ ) zum Abfluß gelangt. Das Ganze ruht in dem Ring eines Dreifußes aus Eisen (Fig. $1 g$ ), der so eingerichtet sein kann, $\mathrm{da} \beta$ er Apparate von verschiedener Größe aufzunehmen imstande ist, falls man es nicht vorzieht, sofort einen Apparat von solchem Umfang herstellen zu lassen, der auch den weitestgehenden Ansprüchen in Bezug auf Leistungsfähigkeit entspricht. 
Außerdem empfiehlt es sich, eine Kiste von der in der Figur 1 dargestellten Form anfertigen zu lassen. Das obere kleine Brett trägt ein kreisförmiges Loch (Fig. $1 \mathrm{~h}$ ). Im Hohlraum der Kiste selbst kann ein Brett (Fig. $1 k$ ) in beliebiger Höhe auf entsprechend hohe Holzleisten (Fig. $1 i$ ) aufgelegt werden.

Bei der Konstruktion des Apparates müssen folgende Punkte berücksichtigt werden. Zunächst ist darauf zu achten, daß der Gashahn eine recht weite Bohrung besitzt. Alsdann müssen die beiden Trichter sauber an den gemeinsamen Zylinder angelötet werden, so daß im Innern keine vorspringenden Ränder entstehen, auf denen sich Sand niedersetzen kann, der nicht vom aufströmenden Wasser erreicht werden würde. Außerdem ist darauf zu achten, daß die Wand des oberen Trichters in einem Winkel von ca. $45^{\circ}$ gegen die Achse des Zylinders geneigt ist, da bei stärkerer Neigung der emporgewirbelte Sand leicht auf der inneren Trichterwand liegen bleibt und nicht gehörig gereinigt wird. Der Wert des Trichters beruht darin, daß die vom emporsteigenden Wasserstrom mitgerissenen Sandteilchen nicht über dessen Rand hinübergeschwemmt werden, da die Bewegung der Wasserteilchen in den Rändpartien des Trichters eine verhältnismäßig ruhige ist, so $\mathrm{da} B$ die Sandteilchen hier untersinken, unten wieder erfaßt und emporgetragen werden. Ist das Ableitungsrohr nicht weit genug, so kann es vorkommen, daß das ringförmige Gefäß sich mit Wasser füllt und dieses den verbotenen Weg über den Rand hinweg einschlägt. Die Verbindung des Hahns der Wasserleitung mit dem Gashahn muß durch einen Schlauch erfolgen, der den Druck der Wasserleitung aushält, sobald der Gashahn geschlossen wird. Es gibt geeignete Klemmvorrichtungen, die ein Losspringen des Schlauches von einem der beiden Hähne verhindert.

Ist der Apparat mit Sand z. B. beschickt - bevor dies geschieht, muß aler Gashahn geschlossen werden -, so öffnet man zunächst den Wasserhahn, alsdann den Gashahn und läßt den regulierten Wasserstrom so lange den Sand emporwirbeln, bis das Wasser oben im Trichter kristallklar ist. Dann verschließt man zunächst den Gashahn, dann den Wasserhahn. Nach Entfernung des Schlauches am Gashahn öffnet man diesen und läßt den Sand mit dem Wasser in ein Gefäß, das man auf ein Brett (Fig. $1 k$ ) gestellt hat, fließen. Sollte in dem Ausfließen des Sandes eine Unterbrechung eintreten, so empfiehlt es sich, reines Wasser von oben in den Zylinder zu gießen, es fließt der Sand dann weiter fort.

Die beiden Figuren verdanke ich der Freundlichkeit des Herrn Zeichenlehrer Reinhold Gundlach. 